\title{
The Lion Heart of a Neurosurgeon: the Stress during a Life of Neurosurgery
}

\author{
Dana Mihaela Turliuc ${ }^{1,2}$, Claudia Florida Costea ${ }^{1,2}$, Ş. Turliuc ${ }^{2}$, \\ R.A. Sascău ${ }^{2,3}$, Emilia Pătrăşcanu ${ }^{2,4}$, I. Poeată ${ }^{1,2}$, A.I. Cucu ${ }^{1}$ \\ 1"Prof. Dr. N. Oblu" Emergency Clinical Hospital, Iași, ROMANIA \\ 2"Grigore T. Popa" University of Medicine and Pharmacy, Iași, ROMANIA \\ 3"George I. M. Georgescu" Institute of Cardiovascular Diseases, Iasi, ROMANIA \\ ${ }^{4}$ Regional Institute of Oncology, Iasi, ROMANIA
}

"A good surgeon must have an eagle's eye, a lion's heart and a lady's hand". (old English proverb)

\begin{abstract}
Neurosurgery is a rewarding career choice in which there are many challenges and stress factors that can lower the level of satisfaction and also increase the levels of burnout. The identification and management of common work-related stressors is important for improving the performance of health-care specialists and also for providing high-quality patient care.
\end{abstract}

\section{Introduction}

It is well-known that surgeons work in a stressful environment due to the multiple surgical challenges, technical requirements and time pressure they have to face on a daily basis [16,53]. They also experience complex crisis situations while performing surgical procedures, which can inevitably lead to acute stress, with direct effects on patient outcomes [19,51]. Despite all these stressful factors, neurosurgery was and will always be a rewarding specialization [33].

\section{Exhaustion and Burnout Syndrome}

In 2015, the American neurosurgeon McAbee et al. published a recent nationwide study from USA where he reported a significant $57 \%$ of American neurosurgeons who met the burnout syndrome criteria [33].

This condition is defined as a clinical syndrome characterized by a high degree of emotional exhaustion and depersonalization and a low sense of personal accomplishment with negative consequences on the surgeon's state of health and on the patient's postoperative evolution $[11,12,13,21,31,32$, 33]. Also, the burnout syndrome has been 
included in the International Statistical Classification of Diseases and Related Health Problems 10th Revision (ICD-10), and its symptoms are: exhaustion, fatigue, cynicism, poor judgment, feelings of ineffectiveness and disconnection with patients and colleagues $[10,11,41]$, but also lower quality of care for patients [52].

The prevalence of burnout is $40 \%$ in surgical specialties $[5,6,7]$, being the greatest during the years of training [17], with residents being the most exposed of all doctors [39], as more than half of them are affected [52]. As concerns the field of neurosurgery, the prevalence of the burnout syndrome was estimated to range between 27 and $56.7 \%$, with the highest rate among all surgical subspecialties [27,33]. This is accounted for by the fact that neurosurgery training is long-lasting, competitive, with the longest training programs of all specialties and the third most competitive specialty $(76 \%)$ after vascular surgery $(71 \%)$ and orthopedics (75\%) [37]. Moreover, neurosurgery residents tend to work more than other residents in other specialties, as evidenced by the Accreditation Council for Graduate Medical Education in the USA with duty hours up to $88 \mathrm{~h} / \mathrm{wk}$, which is $10 \%$ above the $80 \mathrm{~h}$ limit for the other specialties [34].

The best demographic predictor of burnout syndrome is the number of hours worked per week, although many factors have been taken into account such as: hours slept per night and nights/weekends worked per month [17], number of nights on call per week (8), younger age [28], or even the specialty practice area $[5,6,7]$.
Also, the burnout syndrome is associated with substance abuse, suicidal ideation, medical errors, impairment of interpersonal relationships or even desire by young surgeons to retire early $[9,14,42,43,49,50]$, anxiety and depression [5]. Also, patients who have been treated by surgeons suffering from burnout are most often unhappy with the level of healthcare received [9].

As far as the level of satisfaction of doctors is concerned, the most unsatisfied surgeons are those who do not have time for their personal life or family $[5,6,7,41]$ or work in private practice [6], and the most satisfied were reported to be those who have enough time for non-patient care activities [5,6,7,28], the eldest [28], those who spend more time in the operating theater [44], or those who teach at university [6]. In this regard, McBee demonstrated that neurosurgeons who are also academics have a lower rate of burnout than nonacademic neurosurgeons [33], which shows that neurosurgeons feel more satisfied if they are challenged at their work place.

In 2015, McBee et al. demonstrated that factors that increase the satisfaction in a neurosurgeon's career are: having children, being surgically productive, being intellectually stimulated, and a balance between their neurosurgeon careers and life outside of work [33].

\section{Stress}

In 1936, Hines and Brown were among the first to assume that mental stress can lead to hypertension, influencing cardiovascular activity by increasing their heart rate (HR) and blood pressure (BP) [20]. Another 
research conducted in 2002 industrial workers proved a 2.2 times higher risk of cardiovascular events and mortality in high job stress employees compared to their low job stress colleagues [24].

When individuals are exposed to workplace risk factors, their reaction to stress may be emotional, behavioral, cognitive and physiological [45]. Thus, although low levels of stress may enhance alertness and efficiency of tasks [25], excessive and acute stress levels during surgery may affect attention [26], concentration and motor skills $[2,3,15]$, may interfere with manual dexterity [2,3], cognitive functioning [36] and memory retrieval [29].

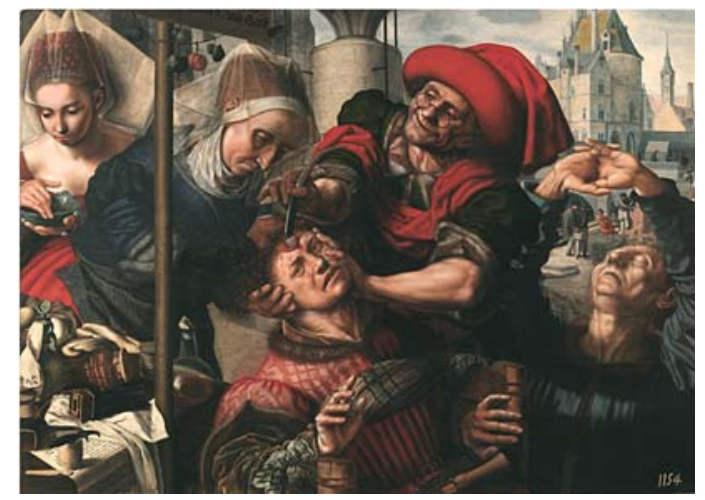

El cirujano (The surgeon), Jan Sanders van Hemessen. Madrid, Museo del Prado (between 1550-1555) (public domain)

This is of major importance, since for the purpose of performing a safe surgical procedure, it is necessary to integrate complex cognitive processes with manual dexterity [4]. Studies have shown that all these pathophysiological changes that occur in prolonged stress may lead to anxiety, depression, alcoholism, substance abuse, broken relationships or even suicide, all of which are more common among surgeons and physicians than in other professions [9].

Also, with regard to surgical professions, studies have shown that the constant intraoperative fluctuation of BP and HR may increase the risk for coronary events [23], cerebrovascular disease [22], diabetes (35) and impairment of cognitive functioning and structural brain changes $[18,38]$ or depression [47]. A recent study in orthopedic surgeons has shown that the BP of trainees was much higher when they performed surgery alone than when they performed it under supervision [18].

As concerns the high levels of stress during surgery, studies have shown that they are specific, higher in surgical residents and young specialists, and are attributed to the novelty of the procedures [18], and on the other hand, experienced surgeons are accustomed to the stress of surgery under pressure and intraoperative complications $[12,13]$.

\section{Cardiovascular Disease}

Cardiovascular diseases are among the most common causes of death among doctors, including surgeons. When stress reaction persists for a long time, neurosurgeons may develop cardiovascular disease, chronic fatigue or musculoskeletal disorders due to the activation of the sympathoadrenal system and the hypothalamic-pituitary-adrenocortical axis leading to hyperlipidemia, atherosclerosis, hypertension and hence coronary heart 
disease [45]. Interestingly enough, the cardiovascular response to intraoperative stress differs from that induced by exercise. In this respect, the increased $\mathrm{BP}$ incidence (SBP/DBP > 180/90mmHg) was higher during surgery, whereas the tachycardia rate was higher during exercise [45].

The surgeon's cardiovascular response to surgical procedures undoubtedly varies during the surgical procedures, being higher in more difficult surgical procedures or in the critical phases of the surgery $[18,46]$. Thus, Sharma et al. reported higher incidence of abnormal BP elevation episodes during vestibular schwannoma excision and aneurysm clipping surgeries, compared to the rest of neurosurgical procedures on the brain [45].

Bunevicius et al. found that during brain aneurysm surgery, if the procedure is divided into seven surgical phases (1 - before skin incision, 2 - after craniotomy, 3 - after dural opening, 4 - after aneurysm neck dissection, 5 - after aneurysm clipping, 6 - after dural closure, 7 - after skin closure), the highest HR and BP (systolic, diastolic and mean BP) occurred during and after the aneurysm neck dissection and clipping phases. These were followed by a gradual decline and return to normal levels. Interestingly enough, intraoperative cardiovascular and hemodynamic response was independent of the neurosurgeon's experience $[12,13]$.

\section{Conclusion}

Mental stress and work-related stress management in the operating theater has important implications for both the neurosurgeon's health and the safety of the patient. From this point of view, it is important to find factors that increase personal satisfaction and reduce mental stress. In this respect, an alternative found in recent years has been to listen to one's favorite music in the operating theater [40], which seems that even improves performance and reduces autonomic reactivity [1]. Since there have also been studies showing that music in the operating theater may lead to distraction [30,48], further research is required in this direction.

\author{
Correspondence \\ Claudia Florida Costea \\ "Prof. Dr. N. Oblu" Emergency Clinical Hospital, \\ Iaşi, Romania \\ E-mail:costea10@yahoo.com
}

\section{References}

1. Allen $\mathrm{K}$, Blascovich J. Effects of music on cardiovascular reactivity among surgeons. JAMA. 1994; 272:882-884.

2. Arora S, Sevdalis N, Nestel D, et al. The impact of stress on surgical performance: a systematic review of the literature. World J Surg. 2010; 147:318-330.

3. Arora S, Sevdalis N, Aggarwal R, et al. Stress impairs psychomotor performance in novice laparoscopic surgeons. Surg Endosc. 2010; 24:2588-2593.

4. Arora S, Sevdalis N, Suliman I, et al. What makes a competent surgeon? Experts' and trainees' perceptions of the roles of a surgeon. Am J Surg. 2009; 198:726-732.

5. Balch CM, Oreskovich MR, Dyrbye LN, et al. Personal consequences of malpractice lawsuits on American surgeons. J Am Coll Surg. 2011; 213:657-667.

6. Balch CM, Shanafelt TD, Sloan JA, Satele DV, Freischlag JA. Distress and career satisfaction among 14 surgical specialties, comparing academic and private practice settings. Ann Surg. 2011; 254:558-568. 
7. Balch CM, Shanafelt TD, Sloan J, Satele DV, Kuerer HM. Burnout and career satisfaction among surgical oncologists compared with other surgical specialties. Ann Surg Oncol. 2011; 18:16-25.

8. Balch CM, Shanafelt TD, Dyrbye L, et al. Surgeon distress as calibrated by hours worked and nights on call. J Am Coll Surg. 2010; 211:609-619.

9. Balch CM, Freischlag JA, Shanafelt TD. Stress and burnout among surgeons: understanding and managing the syndrome and avoiding the adverse consequences. Arch Surg. 2009; 144:371-376.

10. Balch CM, Copeland E. Stress and burnout among surgical oncologists: a call for personal wellness and a supportive workplace environment. Ann Surg Oncol. 2007; 14:3029-3032.

11. Bittner JG IV, Khan Z, Babu M, Hamed O. Stress, burnout, and maladaptive coping: strategies for surgeon well-being. Bull Am Coll Surg. 2011; 96:17-22.

12. Bunevicius A, Bilskiene D, Macas A, Tamasauskas A. Hemodynamic response during aneurysm clipping surgery among experienced neurosurgeons. Acta Neurochir. 2016; 158(2): 221-227.

13. Bunevicius A, Tamasauskas A. Stress during neurosurgery: no need to worry?Acta Neurochir. 2016; 158: 623-624.

14. Campbell DA Jr, Sonnad SS, Eckhauser FE, Campbell KK, Greenfield LJ. Burnout among American surgeons. Surgery. 2001; 130:696-705.

15. Flin R, O'Connor P, Crichton M. Safety at the sharp end: a guide to non-technical skills. Ashgate, Aldershot. 2008.

16. Georgiou K, Larentzakis A, Papavassiliou AG. Surgeons' and surgical trainees' acute stress in real operations or simulation: A systematic review. Surgeon. 2017; 15(6):355-365.

17. Golub JS, Weiss PS, Ramesh AK, Ossoff RH, Johns MM 3rd. Burnout in residents of otolaryngology-head and neck surgery: a national inquiry into the health of residency training. Acad Med. 2007; 82(6):596-601.

18. Gupta HO, Gupta S, Carter RL, Mohammed A, Meek RM. Does orthopaedic surgical training induce hypertension? A pilot study. Clin Orthop Relat Res. 2012; 470:3253-3260.

19. Gurman GM, Klein M, Weksler N. Professional stress in anesthesiology: a review. J Clin Monit Comput. 2012; 26:329-335.
20. Hines EA, Brown GE. The cold pressor test for measuring the reactivity of the blood pressure: data concerning 571 normal and hypertensive subjects. Am Heart J. 1936; 11:1-9.

21. Honkonen T, Ahola K, Pertovaara $\mathrm{M}$, et al. The association between burnout and physical illness in the general population-results from the Finnish Health 2000 Study. J Psychosom Res. 2006; 61:59-66.

22. Huang Y, Xu S, Hua J, et al. Association between job strain and risk of incident stroke: a metaanalysis. Neurology. 2015; 85(19):1648-1654.

23 Kivimäki M, Batty GD, Ferrie JE, Kawachi I. Cumulative meta-analysis of job strain and CHD. Epidemiology. 2014; 25(3):464-465.

24. Kivimäki $\mathrm{M}$, Leino-Arjas $\mathrm{P}$, Luukkonen $\mathrm{R}$, et al. Work stress and risk of cardiovascular mortality: prospective cohort study of industrial employees. BMJ. 2002; 325:857.

25. Klein G. Sources of power. How people make decisions. MIT Press, Cambridge, MA. 1998.

26. Klein G. The effects of acute stress on decision making. In: Driskell JE, Salas E (eds) Stress and human performance. Lawrence Erlbaum Associates, Mahwah. 1996.

27. Klimo P, Decuypere M, Ragel BT, et al. Career satisfaction and burnout among U.S. neurosurgeons: a feasibility and pilot study. World Neurosurg. 2013; 80(5):e59-68.

28. Kuerer HM, Eberlein TJ, Pollock RE, et al. Career satisfaction, practice patterns and burnout among surgical oncologists: report on the quality of life of members of the Society of Surgical Oncology. Ann Surg Oncol. 2007; 14:3043-3053.

29. Kuhlmann S, Piel M, Wolf OT. Impaired memory retrieval after psychosocial stress in healthy young men. J Neurosci. 2005; 25:2977-2982.

30. Lee JY, Lantz AG, McDougall EM, et al. Evaluation of potential distractors in the urology operating room. J Endourol. 2013; 27:1161-1165.

31. Maslach C, Schaufeli WB, Leiter MP. Job burnout. Annu Rev Psychol. 2001; 52:397-422.

32. Maslach CJS, Leiter M. Maslach Burnout Inventory Manual, Consulting Psychologists Press, Palo Alto. 1996. 33. McAbee JH, Ragel BT, McCartney S, et al. Factors associated with career satisfaction and burnout among US neurosurgeons: results of a nationwide survey. J Neurosurg. 2015; 123:161-173. 
34. Muscatello MR, Bruno A, Carroccio C, et al. Association between burnout and anger in oncology versus ophthalmology health care professionals. Psychol Rep. 2006; 99(2):641-650.

35. Nyberg ST, Fransson EI, Heikkila K, et al. Job strain as a risk factor for type 2 diabetes: a pooled analysis of 124,808 men and women. Diabetes Care. 2014; 37:22682275.

36. Raio CM, Brignoni-Perez E, Goldman R, Phelps EA. Acute stress impairs the retrieval of extinction memory in humans. Neurobiol Learn Mem. 2014; 112:212-221.

37. Rakovec-Felser Z. Professional burnout as the state and process-what to do? Collegium antropologicum. 2011; 35(2):577-585.

38. Rothwell PM, Howard SC, Dolan E, et al. Prognostic significance of visit-to visit variability, maximum systolic blood pressure, and episodic hypertension. Lancet. 2010; 375:895-905.

39. Shakir HJ, McPheeters MJ, Shallwani H, Pittari JE, Reynolds RM. The Prevalence of Burnout Among US Neurosurgery Residents.Neurosurgery. 2017; Oct 27.

40. Shambo L, Umadhay T, Pedoto A. Music in the operating room: is it a safety hazard? AANA J. 2015; 83:43-48.

41. Shanafelt T, Dyrbye L. Oncologist burnout: causes, consequences, and responses. J Clin Oncol. 2012; 30:1235-1241

42. Shanafelt T, Sloan J, Satele D, Balch C. Why do surgeons consider leaving practice? J Am Coll Surg. 2011; 212:421-422.

43. Shanafelt TD, Balch CM, Bechamps G, et al. Burnout and medical errors among American surgeons. Ann Surg. 2010; 251:995-1000.

44. Shanafelt TD, Balch CM, Bechamps GJ, et al. Burnout and career satisfaction among American surgeons. Ann Surg. 2009; 250:463-471.
45. Sharma MS, Thapa A, Chandra SP, et al. Intraoperative pulse and blood pressure recordings of neurosurgeons: a pilot study of cardiovascular performance. Neurosurgery. 2010; 66:893-899.

46. Song MH, Tokuda Y, Nakayama T, Sato M, Hattori $\mathrm{K}$. Intraoperative heart rate variability of a cardiac surgeon himself in coronary artery bypass grafting surgery. Interact Cardiovasc Thorac Surg. 2009; 8:639641.

47. Stansfeld SA, Shipley MJ, Head J, Fuhrer R. Repeated job strain and the risk of depression: longitudinal analyses from the Whitehall II study. Am J Public Health. 2012; 102:2360-2366.

48. Way TJ, Long A,Weihing J, et al. Effect of noise on auditory processing in the operating room. J Am Coll Surg. 2013; 216:933-938.

49. West CP, Huschka MM, Novotny PJ, et al. Association of perceived medical errors with resident distress and empathy: a prospective longitudinal study. JAMA. 2006; 296:1071-1078.

50. Williams ES, Manwell LB, Konrad TR, Linzer M. The relationship of organizational culture, stress, satisfaction, and burnout with physician-reported error and suboptimal patient care: results from the MEMO study. Health Care Manage Rev. 2007; 32:203-212.

51. Wong SW, Smith R, Crowe P. Optimizing the operating theatre environment. ANZ J Surg. 2010; 80:917-924.

52. Thomas NK. Resident burnout. JAMA. 2004; 292:2880-2889.

53. Turliuc D, Turliuc S, Cucu A, Buraga V, Costea CF. Claiming dignity while dangling between life and death. Romanian Journal of Artistic Creativity. 2015; 1:34-38. 